\title{
KẾT QUẢ NGẮN HẠN CỦA KỸ THUẬT TỐI ỦU HÓA VÒNG VAN ĐỘNG MẠCH PHỔI TRONG PHẪU THUẬT TRIỆT ĐỂ TỨ CHÚNG FALLOT
}

\section{TÓM TÁ́T}

Có 42 trường hợp, 24 nam và 18 nữ từ 07 đến 122 tháng, cân nặng lúc phẫu thuật từ 04 đến $24 \mathrm{~kg}$. Tỉ lệ phẫu thuật lại sớm là 2,4\%, tỉ lệ hở van ĐMP vừa (độ 2) là $11,9 \%$, hở nặng (độ 3 ) là $4,8 \%$. Hẹp van ĐMP nhẹ là $64,3 \%$, hẹp trung bình là $21,4 \%$ và hẹp nặng là $0 \%$ khi đo trực tiếp trong phẫu thuật. Suy tim cấp là $19 \%$ và $25 \%$ các trường hợp suy tim cấp dẫn đến tử vong. Phù phổi cấp là $9,5 \%$ và $50 \%$ các trường hợp phù phổi cấp dẫn đến tử vong. Không có block nhĩ thất hoàn toàn. Kỹ thuật tối ưu hóa vòng van ĐMP trong phẫu thuật triệt để tứ chứng Fallot giúp tăng tỉ lệ bảo tồn vòng van đối với các trường hợp giá trị $Z$ vòng van ĐMP từ -3 đến 0 . Tỉ lệ hở và hẹp van ĐMP thấp. Tứ chứng Fallot, Giá trị $Z$ vòng van động mạch phổi, Tối ưu hóa vòng van động mạch phổi.

\section{SUMMARY}

SHORT-TERM RESULTS OF OPTIMIZED TECHNIQUE OF PULMONARY ANNULUS IN COMPLETE REPAIR OF TETRALOGY

There were 42 cases, 24 men and 18 women from 07 to 122 months, weight from 4 to $24 \mathrm{~kg}$. The rate of early surgery was $2.4 \%$, the rate of mild pulmonary reguritation (grade 2) was $11.9 \%$, severe (grade 3) was $4.8 \%$. Mild stenosis of pulmonary valve was $64.3 \%$, mean was $21.4 \%$ and severe was $0 \%$ when measured directly in the surgery. Acute heart failure was $19 \%$ and $25 \%$ of cases lead to death. Acute pulmonary edema was $9.5 \%$ and $50 \%$ of acute lead to death. No complete AV block. Optimized technique of pulmonary annulus in complete repair of tetralogy increase the ratio of preservation of of pulmonary annulus with the $\mathrm{Z}$
Nguyễn Đức Tuấn*, Nguyễn Hoàng Định**

score from -3 to 0 . The rate of reguritation and residual stenosis of pulmonary valve was low.

Keywords: tetralogy, $\mathrm{Z}$ score, optimized technique of pulmonary annulus.

\section{I. ĐẶT VẤN ĐỀ}

Bảo tồn vòng van động mạch phổi (ĐMP) trong phẫu thuật triệt để Tứ chứng Fallot mang lại nhiều ưu điểm đã được chứng minh (7), (10). Theo các tác giả Bắc $M y ̃$ thì dựa vào giá trị $Z$ của vòng van ĐMP để quyết định (10).Nếu $Z<-3$ thì khuyên phải đặt miếng vá xuyên vòng van ĐMP, nếu $Z \geq-3$ thì không cần. Tuy nhiên, theo Kirklin, với $Z$ từ -3 đến 0 thì có từ $3-39 \%$ cần phải phẫu thuật lại trong giai đoạn hậu phẫu sớm để đặt miếng vá xuyên vòng van ĐMP (10).

Trong nỗ lực tìm kiếm giải pháp thích hợp nhằm giảm tỉ lệ phải mổ lại cho nhóm bệnh nhân có $Z$ từ -3 đến 0 . Chúng tôi đã đặt miếng vá ĐMP trùm qua vòng van thay vì kết thúc ngay trên vòng van như trước đây và gọi đây là kỹ thuật tối ưu hóa vòng van với kỳ vọng giảm tỉ lệ phải phẫu thuật lại trong giai đoạn hậu phẫu sớm.

\section{II. ĐỐI TƯợNG - PHƯỚG PHÁP NGHIÊN CÚU}

\section{1 Đối tượng}

Trẻ được chẩn đoán Tứ chứng Fallot, trên 06 tháng tuổi với giá trị $Z$ vòng van ĐMP từ -3 đến 0 ngay trong lúc phẫu thuật từ 08-2013 đến 03-2017.

\subsection{Cõ̃ mẫu \\ Mô tả loạt ca}

* BV Nhi Đồng 1

** Bộ môn Ngoại Lồng ngưc-Tim mạch - Truò̀ng ĐH Y Dược TP HCM Ngưòi chịu trách nhiệm khoa hoc: PGS.TS. Nguyễn Hoàng Định Ngày nhận bài: 01/05/2018 - Ngày Cho Phép Đăng: 20/05/2018

Phản Biện Khoa học: PGS.TS. Đặng Ngoc Hùng GS.TS. Lê Ngoc Thành 
Tất cả các trẻ thỏa tiêu chí ở mục đối tượng và tiêu chí chọn mẫu.

2.3. Tiêu chí chọn mẫu và công thức hiệu chỉnh vòng van động mạch phổi

Trong quá trình phẫu thuật, vòng van ĐMP nguyên thủy (a) sẽ được đo bằng que Hegar và qui đổi ra giá trị $Z$, nếu từ -3 đến 0 sẽ được chọn vào lô nghiên cứu. Kỹ thuật tối ưu hóa vòng van là quá trình miếng vá được trùm lên một phần phễu ĐMP một đoạn (b). Khi đó đường kính vòng van ĐMPtân tạo (sau hiệu chỉnh) được tính theo công thức $\mathrm{c}=\sqrt{a^{2}+b^{2}}$ (Hình 1).

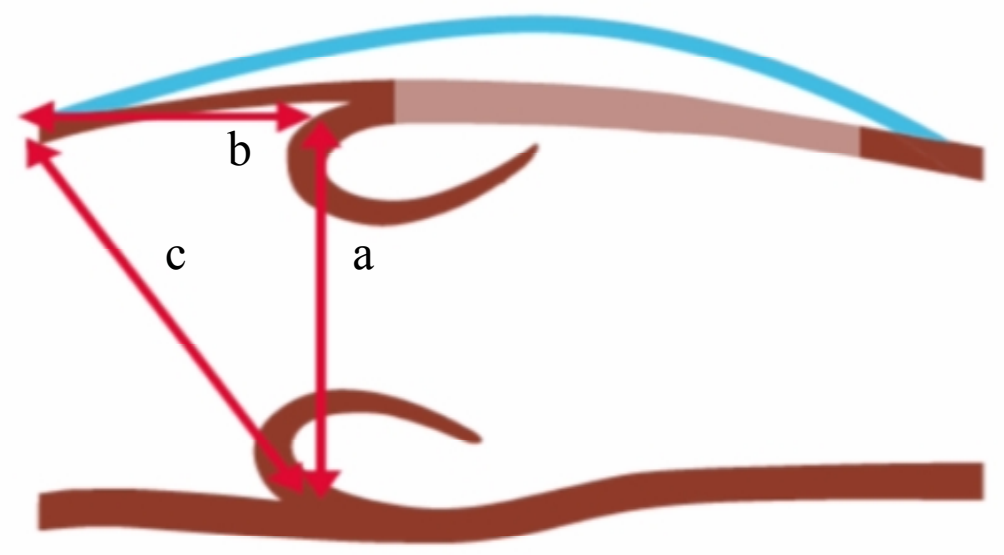

Hình 1. Thiết diệt cắt dọc qua van động mạch phổi

\subsection{Mục tiêu nghiên cứu}

Xác định tỉ lệ cần phẫu thuật lại sớm của kỹ thuật tối ưu hóa vòng van ĐMP trong phẫu thuật triệt để tứ chứng Fallot. Tìm mối tương quan giữa giá trị $Z$ và tỉ số áp lực giữa thất phải và thất trái $\mathrm{P}(\mathrm{RV} / \mathrm{LV})$. Kết quả ngắn hạn về tỉ lệ và mức độ hở - hẹp van ĐMP, tỉ lệ suy tim, phù phổi cấp, rối loạn nhịp và tử vong.

\section{KẾT QUẢ}

\section{1. Đặc điểm lô nghiên cứu}

- Giới tính: Nam 24 trường hợp $(57,1 \%)$; Nữ 18 trường hợp $(42,9 \%)$

- Tuổi lúc phẫu thuật: nhỏ nhất là 7 tháng; lớn nhất là 122 tháng

- Cân nặng lúc phẫu thuật: thường gặp nhất là $11(\mathrm{~kg})$; nhẹ nhất là $4(\mathrm{~kg})$; nặng nhất là $24(\mathrm{~kg})$

\subsection{Các biến số liên quan đến mục tiêu} nghiên cứu

- Z vòng van ĐMP trong phẫu thuật (trước hiệu chỉnh)là $-1,0 \pm 0,4$ và sau hiệu chỉnh là $0,6 \pm 0,4$. Sự khác biệt bài có ý nghĩa thống kê $(\mathrm{p}=0.0001)$

- Sau khi hiệu chỉnh, $Z$ vòng van ĐMP $\leq 0$ là 4 trường hợp $(9,5 \%) ; Z$ vòng van $Đ M P>0$ là 38 trường hợp $(90,5 \%)$

- Phù phổi cấp sau phẫu thuật: có 4 trường hợp $(9,5 \%)$

- Suy tim cấp sau phẫu thuật: Có 8 trường hợp (19\%), trong đó có 2 trường hợp tử vong (25\%)

- Block nhĩ thất sau phẫu thuật: $0 \%$

Hở van ĐMP sau phẫu thuật dựa trên siêu âm. 
Bảng 1. Phân bố mức độ hở van ĐMP sau phẫu thuật dựa trên siêu âm

\begin{tabular}{lcc}
\hline & Tần số & Tỉ lệ (\%) \\
\hline Không hở & 16 & 38,1 \\
\hline Hở độ 1 & 19 & 45,2 \\
\hline Hở độ 2 & 5 & 11,9 \\
\hline Hở độ 3 & 2 & 4,8 \\
\hline
\end{tabular}

- Hẹp van ĐMP sau phẫu thuật

Bảng 2. Phân bố mức độ hẹp van ĐMP

\begin{tabular}{lcccc} 
& \multicolumn{2}{c}{ Đo trực tiếp } & \multicolumn{2}{c}{ Đo qua siêu âm } \\
\hline Thàn số & Tỉ lệ (\%) & Tần số & Tỉ lệ (\%) \\
\hline Hẹp nhẹ & 6 & 14,3 & 4 & 9,5 \\
\hline Hẹp trung bình & 27 & 64,3 & 26 & 61,9 \\
\hline
\end{tabular}

Sự khác biệt này không có ý nghĩa thống kê qua kiểm định $\mathrm{McNemar}-$ Bowker với $\mathrm{p}=0,688$

- Mối tương quan giữa $Z$ vòng van ĐMP sau phẫu thuật với tỉ số áp lực tâm thu của RV/LV

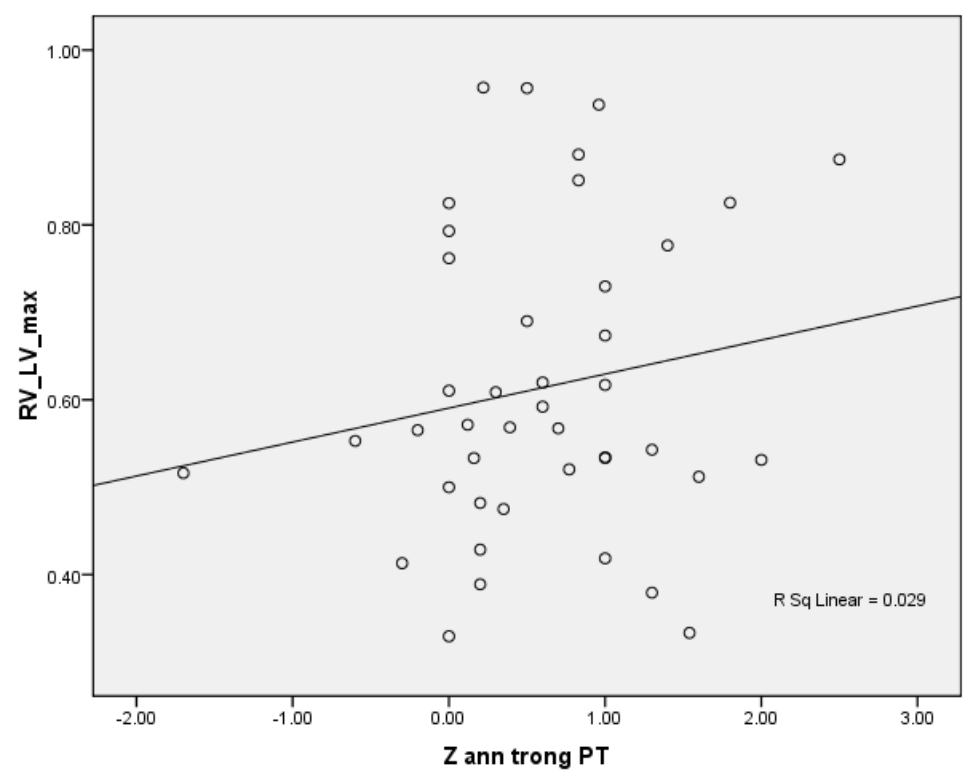

Biểu đồ 1. Biểu đồ tuyến tính 
- Tỉ lệ tử vong: $2 / 42$ trường hợp (4,8\%)

- Tỉ số áp lực tâm thu giữa thất phải và thất trái: $\mathrm{P}(\mathrm{RV} / \mathrm{LV}) \leq 0,7$ có 30 trường hợp $(71,4 \%)$; $\mathrm{P}(\mathrm{RV} / \mathrm{LV})>0,7$ có 12 trường hợp $(28,6 \%)$

- Tỉ lệ tử vong: $1 / 42$ trường hợp $(2,4 \%)$

\section{BÀN LUẬN}

\section{1 Đặc điểm lô nghiên cứu}

\subsubsection{Giới tính}

Trong 42 bệnh nhân của lô nghiên cứu này, Nam chiếm ưu thế hơn với $57,1 \%$ so với Nữ là $42,9 \%$, kết quả này tương đương với báo cáo của tác giả Phan Cao Minh (16) và y văn nước ngoài (18).

\subsubsection{Tuổi lúc phẫu thuật}

Tuổi được phẫu thuật triệt để không tập trung mà trải đều từ 7 tháng tuổi đến 122 tháng. Trong đó dưới 1 tuổi là $23,8 \%$ và trên 1 tuổi là $76,2 \%$.

Theo Phan Cao Minh, tuổi trung bình là $22,5 \pm 15,8$ tháng (16) cho thấy tuổi phẫu thuật thời điểm đó cũng phân tán chứ không tập trung.

Đối với tứ chứng Fallot, tuổi phẫu thuật triệt để phụ thuộc rất nhiều vào nguồn lực của từng trung tâm như kỹ năng của phẫu thuật viên, khả năng của chạy tuần hoàn cơ thể và của gây mê hồi sức. Trong nhiều báo cáo của nước ngoài, tuổi phẫu thuật được hạ xuống dưới 12 tháng bởi vì nó có nhiều ưu điểm (9), (10), (3). Tuy nhiên, theo Glen S Van Arsdell, tuổi phẫu thuật được khuyến cáo là từ 03 tháng đến 11 tháng (3).

Do đó, ngoài những ưu điểm do phẫu thuật triệt để sớm mang lại như: đảm bảo cung cấp oxy cho não phát triển trong những tháng đầu đời; giảm các biến chứng suy tim, áp xe não, viêm nội tâm mạc nhiễm trùng . . . thì việc phâuu thuật triệt để quá sớm sẽ làm bệnh nhân đối mặt với rất nhiều nguy cơ như tác giả Edward $\mathrm{P}$. Walsh đã báo cáo (1). Một trường phái khác được đưa ra bởi các tác giả Nhật bản là sử dụng thông nối chủ - phổi (BT shunt)như một phương pháp vừa đảm bảo được những ưu điểm của việc phẫu thuật sớm mang lại vừa đảm bảo cho van ĐMP, các mạch máu phổi và thể tích thất trái phát triển tốt (14).

Mặc dù có nhiều tranh luận nhưng hầu hết các tác giả thống nhất rằng phẫu thuật triệt để tứ chứng Fallot tốt nhất từ 04 đến 12 tháng tuổi (10).

\subsubsection{Cân nặng lúc phẫu thuật}

Cân nặng thường gặp nhất là $11(\mathrm{~kg})$. Cân nặng nhẹ nhất là $4(\mathrm{~kg})$. Theo Phan Cao Minh thì cân nặng lúc phẫu thuật là 9,05 $\pm 2,98(\mathrm{~kg})(16)$.

\subsection{Các biến số liên quan đến mục tiêu} nghiên cứu

\subsubsection{Tỉ lệ phẫu thuật lại sớm}

Chúng tôi định nghĩa phẫu thuật lại sớm là việc phẫu thuật lại ngay trong giai đoạn bệnh nhân còn nằm trong phòng hồi sức, khi xuất hiện các dấu hiệu đe dọa đến tính mạng bệnh nhân.

Từ định nghĩa trên, nếu xét trên toàn bộ lô nghiên cứu, tỉ lệ phải phẫu thuật lại là 2,4\%. Kết quả này thấp đáng kể so với các báo có khác trong y văn là $3-39 \%$. Tuy nhiên, kết quả của này chỉ là bước đầu, chúng tôi cần nhiều thời gian để có số liệu lớn hơn.

\subsubsection{Chỉ số $Z$ của vòng van ĐMP sau hiệu} chỉnh và mối tuơng quan giữa Zvà tỉ số áp lục giữa thất phải và thất trái $P(R V / L V)$

Chỉ số $Z$ vòng van ĐMP trong phẫu thuật là phân phối chuẩn nhưng có độ phân tán khá lớn. Chỉ số trung bình là $0,6 \pm 0,4$, trong đó giá trị nhỏ nhất là $-1,7$ và lớn nhất là $+2,5$

Về lý thuyết, việc nạo cơ buồng thoát thất phải quá mức sẽ gây mất chức năng co bóp vùng này và gây vận động nghịch thường, góp phần gây hở van ĐMP nặng, về lâu dài sẽ gây dãn tim phải và suy chức năng tâm thu, kéo theo là khả năng rối loạn nhịp và đột tử cao $(7),(10)$. Ngược lại nếu nạo cơ mức độ vừa phải, để lại chênh áp qua van ĐMP sẽ tránh được nguy cơ này, nhưng lại đối mặt với nguy cơ hẹp tồn lưu cao. Người ta cho rằng nếu còn hẹp tồn lưu thì lâu dài gây dầy thất phải thứ phát, chức năng tâm thu 
thường tốt, nhưng chức năng dãn nở bị ảnh hưởng nhiều (4), (10).

Bằng kỹ thuật tối ưu hóa vòng van, phần cơ thất được nạo và gọt mỏng phía dưới van ĐMP thay vì bị vận động nghịch thường thì sẽ được đưa vào trong lòng ĐMP mới và tham gia như một phần lá van nhân tạo tự thân và điều đó giúp hạn chế tối đa hở van ĐMP.

Mặc dù được ứng dụng kỹ thuật tối ưu hóa vòng van ĐMP, tuy nhiên kỳ vọng cải thiện chỉ số $Z \geq 0$ là không thể thực hiện được tất cả các trường hợpmà chỉ chiếm $90,5 \%$. Và có 04 trường hợp $(9,5 \%)$ có $Z<0$ vì khi tối ưu hóa vòng van quá nhiều, tức kéo dài đoạn $\mathrm{b}$ trong Hình 1 , sẽ làm thay đổi hướng đi của dòng máu theo chiều hướng tiêu cực.

Theo biểu đồ 1 cho thấy không phải mở rộng vòng ĐMP càng nhiều thì càng cải thiện tỉ số áp lực tâm thu RV/LV. Thực tế, tỉ số này có thể phụ thuộc vào các yếu tố khác như: Sức co bóp của thất phải; Kháng lực mạch máu phổi; Tuần hoàn bàng hệ chủ - phổi; Sức co bóp của thất trái. Đây cũng là lý do tại sao mà hầu hết phẫu thuật viên ngày nay dựa vào chỉ số $Z$ để quyết định việc bảo tồn vòng van ĐMP hơn là dựa vào tỉ số áp lực tâm thu RV/LV.

Trong lô nghiên cứu này, 12/42 trường hợp $(28,6 \%)$ có tỉ số áp lực tâm thu $\mathrm{RV} / \mathrm{LV}>0,7$ nhưng không có bất kỳ biến chứng sớm nào được ghi nhận, tỉ số cao nhất là 0,96 .

Chúng tôi có hai trường hợp cần phải phẫu thuật lại, $\mathrm{P}(\mathrm{RV} / \mathrm{LV})$ lần lược là 0,57 và 0,6 trong khi chỉ số $Z$ vòng van ĐMP sau hiệu chỉnh lần lượt là $+1,0$ và 0 . Nguyên nhân phẫu thuật lại được xác định là hẹp tồn lưu buồng thoát thất phải.

\subsubsection{Múcc độ hở van ĐMP}

Kỹ thuật tối ưu hóa vòng van ĐMP có tỉ lệ hở van ĐMP vừa (độ 2) là 11,9\% và hở nặng (độ 3) là $4,8 \%$. Đáng chú ý là không hở van ĐMP chiếm $38,1 \%$ (Bảng 1).
Câu hỏi được đặt ra là tình trạng hở van ĐMP có liên quan gì đến hình thái van hay không ? Số liệu trong nghiên cứu này chưa đủ lớn để kiểm định giả thuyết về mối liên hệ giữa tình trạng hở van ĐMP và hình thái van. Tuy nhiên về số tuyệt đối cho thấy số trường hợp hở van ĐMP giảm dần theo độ nặng của hở van.

\subsubsection{Mức độ hẹ van ĐMP}

Bảng 2 cho thấy không có trường hợp nào hẹp nặng trong cả hai phương pháp đo trực tiếp và qua siêu âm. Đa số các trường hợp là hẹp nhẹ với $64,3 \%$ khi đo trực tiếp so với $61,9 \%$ khi đo qua siêu. Hẹp trung bình với 21,4\% khi đo trực tiếp so với $26,8 \%$. Sự khác biệt này không có ý nghĩa thống kê.

Kết quả trên cho thấy tỉ lệ hẹp van cũng giảm dần theo mức độ hẹp. Đây là kết quả theo chúng tôi là chấp nhận được vì bản chất của van động mạch phổi trong tứ chứng Fallot là hẹp. Việc sửa chữa chỉ làm giảm mức độ hẹp mà thôi.

Trong báo các về kết quả phẫu thuật TOF sau 30 năm theo dõi, các tác giả ở Mayo Clinic và ở Munich đều cho thấy rằng tỉ lệ áp lực thất phải / thất trái trên 0,7 có tỉ lệ sống còn cao hơn và tỉ lệ đột tử thấp hơn so với nhóm khác (13). Trong nghiên cứu của các tác giả ở Munich ghi nhận những bệnh nhân có tỉ áp lực tâm thu giữa $\mathrm{RV} / \mathrm{LV}$ $>0,7$ thì có tỉ lệ sống sót sau 30 năm là $94,4 \%$ so với nhóm có $\mathrm{RV} / \mathrm{LV}<0,7$ là $83,7 \%$. Tuy nhiên sự khác biệt này không có ý nghĩa thống kê do số lượng $\mathrm{BN}$ chưa đủ lớn. Họ đồng ý với giả thuyết trước đây rằng một thất phải đủ dày sẽ chịu tải áp lực tốt hơn.

\subsubsection{Tỉ lệ suy tim}

Kết quả lô nghiên cứu của chúng tôi cho thấy $8 / 42$ trường hợp có dấu hiệu suy tim cấp $(19 \%)$ và $2 / 8$ trường hợp có suy tim cấp dẫn đến tử vong $(25 \%)$. Do đó có thể nói suy tim cấp là dấu hiệu sớm cảnh báo nguy cơ tử vong. 
Theo các báo cáo trước đây của Viện tim TP.HCM thì 95\% tử vong do suy tim cấp (6); Viện tim Hà nội và Bệnh viện Trung ương Huế có $60 \%$ tử vong do suy tim cấp (15), (11); Bệnh viện Nhi đồng 1 là 53,3\% (16); Nghiên cứu này $100 \%$ tử vong do suy tim cấp.

\subsubsection{Tỉ lệ phù phổi cấp và tử vong}

Kết quả lô nghiên cứu của chúng tôi có 4/42 trường hợp $(9,5 \%)$ có đủ tiêu chuẩn chẩn đoán phù phồi dựa trên $\mathrm{SpO} 2$ giảm, hút nội khí quản có bọt hồng, X_Quang phổi có hình ảnh mờ 2 rốn phổi. Trong một nghiên cứu trước đây tại Bệnh viện Nhi đồng 1 , tỉ lệ này là $8,8 \%$ (16)

Phù phổi cấp có nhiều nguyên nhân, trong đó hai nguyên nhân thường gặp nhất là suy chức năng thất trái và tuần hoàn bàng hệ chủ phổi quá nhiều.

Trong 04 trường hợp có phù phổi cấp, 02 trường hợp cần phải phẫu thuật lại. Chúng tôi xem đây là thất bại của kỹ thuật tối ưu hóa vòng van vì phải đặt mảnh vá xuyên vòng van. Trong đó có 01 trường hợp mặc dù phải mổ lại nhưng chỉ cần gọt mỏng thêm buồng thoát thất phải là các chỉ số huyết động học ổn định, trường hợp này có thể do chúng tôi thiếu kinh nghiệm khi phẫu thuật các trường hợp đầu tiên. Như vậy chỉ có $1 / 42$ trường hợp $(2,4 \%)$ là thực sự phải mổ lại. Cả 02 trường hợp mổ lại đều tử vong sau đó trong bệnh cảnh nhiễm trùng huyết và suy đa cơ quan.

Do đó, nếu xét trên toàn bộ lô nghiên cứu, tỉ lệ phải phẫu thuật lại là $2,4 \%$ và tỉ lệ tử vong là $4,8 \%$

\subsubsection{Tỉ lệ rối loạn nhịp}

Trong lô nghiên cứu này có 2 trường hợp bị block nhĩ thất độ $3(4,8 \%)$ thì cần đặt máy tạo nhịp thượng tâm mạc sau 03 tuần theo dõi mà không trở về nhịp xoang.

Theo các báo cáo trước đây của Viện tim TP.HCM, nghiên cứu trên 1013 có $0,6 \%$ bị block nhĩ thất độ 3 (6) thì nghiên cứu này có tỉ lệ cao hơn. Tuy nhiên số trường hợp trong lô này chưa đủ lớn để có tỉ lệ chính xác hơn.
Trong nhiều báo cáo, rối loạn nhịp ngay sau phẫu thuật thường gặp nhất là block nhánh phải, JET, block nhĩ thất độ 3 . Ít gây tử vong vì dễ phát hiện và điều trị hiệu quả. Đối với block nhánh phải thường không gây rối loạn huyết động gì và cũng không cần điều trị. Rối loạn nhịp trễ sau phẫu thuật thường gặp nhất là các dạng nhịp nhanh nhĩ hoặc nhịp nhanh thất. Tỉ lệ thật sự đến nay chưa biết được. Đây là nguyên nhân gây đột tử chủ yếu, đặc biệt là nhịp nhanh thất. Nguyên nhân gây rối loạn nhịp này chưa rõ, nhưng người ta nghĩ do tổn thương cơ tim gây ra do phẫu thuật, do dãn buồng tim nặng thứ phát sau hở phổi (18), (2), (12), (4), (10), (9), (17), (8).

Trong phẫu thuật triệt để Tứ chứng Fallot, đóng lỗ thông liên thất có thể gặp biến chứng Block nhĩ thất độ 3 . Về kỹ thuật tối ưu hóa vòng van chúng tôi chỉ thực hiện việc nạo phần phễu động mạch phổi và vùng này về lý thuyết không liên quan gì đến đường dẫn truyền trong tim. Vì vậy, hai trường hợp Block $\mathrm{A}-\mathrm{V}$ độ 3 trong lô nghiên cứu này liên quan đến kỹ thuật đóng lỗ thông liên thất nhiều hơn. Có nghĩa là kỹ thuật nạo vét phần phễu động mạch phổi không gây ra Block nhĩ thất độ 3 .

\section{KẾT LUẬN}

Kỹ thuật tối ưu hóa vòng van ĐMP trong phẫu thuật triệt để tứ chứng Fallot giúp tăng đáng kể tỉ lệ bảo tồn vòng van đối với các trường hợp giá trị $\mathrm{Z}$ vòng van ĐMP từ -3 đến 0. Tỉ lệ hở, hẹp van ĐMP thấp.

\section{TÀI LIỆU THAM KHẢO}

1. EP Walsh, S Rockenmacher, JF Keane, TJ Hougen, JE Lock and AR Castaneda (1988), "Late results in patients with tetralogy of Fallot repaired during infancy",Circulation. (77), pp 1062-67.

2. Gatzoulis MA, Till JA, SomervilleJ, Redington AN (1995), "Mechanoelectrical 
interaction in tetralogy of Fallot. QRS prolongation relates to right ventricular size and predics malignant ventricular arrhythmias and sudden death", Circullation. 92(2), pp 231-37.

3. Glen S. Van Arsdell, Gyaandeo S. Maharaj, Julie Tom, Vivek K. Rao, John G. Coles, Robert M. Freedom, William G. Williams and Brian W. McCrindle (2000), "What is the Optimal Age for Repair of Tetralogy of Fallot?", Circulation. (102), pp 123-29.

4. Glen S. Van Arsdell, Tae Jin Yun, Micheal Cheung (2009), "Tetralogy of Fallot: managing the right ventricular outflow", Congenital diseases in the right heart. pp 233-40.

5. Gunnar Norgård, Michael A. Gatzoulis, Fernando Moraes, Christopher Lincoln, Darryl F. Shore, Elliot A. Shinebourne, Andrew N. Redington (1996), "Relationship Between Type of Outflow Tract Repair and Postoperative Right Ventricular Diastolic Physiology in Tetralogy ofFallot: Implications for Long-term Outcome", Circulation. (94), pp 3276-80.

6. Hồ Huỳnh Quang Trí, Nguyễn Minh Trí Viên, Phạm Nguyễn Vinh, Phan Kim Phương, Nguyễn Văn Phan, Văn Hùng Dũng (2006), "Kết quả phẫu thuật triệt để tứ chứng Fallot tại Viện Tim 1992-2004", Tạp chí tim mạch học Việt Nam số 45, trang 41-52.

7. Hoàng Trọng Kim (1995), "Tứ chứng Fallot", Nhi khoa Đà Nẵng, ĐHYD TP.HCM, tập 1 , trang 88-98.

8. J. Therrien, S. C. Siu, L. Harris, A. Dore, K. Niwa, J. Janousek, W. G.Williams, G. Webb (2001), "Impact of Pulmonary Valve Replacement on Arrhythmia Propensity Late After Repair of Tetralogy of Fallot", Circulation.(103), pp 2489-94

9. Kirklin JK, Blackstone EH, Milano A, Pacifico AD (1989), "Effect of transannular patching on outcome affter repair of tetralogy of Fallot”, Ann Thorac Surg. (48), pp 783-71.

10. Kirklin, Barratt-Boyes (2003), "Ventricular septal defect with pulmonary stenosis or atresia", Cardiac Surgery. 3rd, pp 946-92.

11. Lê Quang Thửu (2010), “Đánh giá kết quả phẫu thuật sửa chữa toàn phần bệnh tứ chứng Fallot qua đường nhĩ phải-động mạch phổi”, Luận án Tiến sĩ y học, Học viện Quân y.

12. M. S. Gotsman, W. Beck, C. N. Barnard, T. G. O'donovan V. Schrire (1969), "Results of Repair of Tetralogy of Fallot", Circulation. (40), pp 803-22.

13. Murphy JG, Gersh BJ, Mair DD, Fuster V, McGoon MD, Ilstrup DM, Kirklin JW, Danielson GK (1993), "Long-term outcome in patients undergoing surgical repair of tetralogy of Fallot", New England J med. (329), pp 593-599.

14. Nakashima K, Itatani K, Oka N, Kitamura T, Horai T, Hari Y, Miyaji K (2014), "Pulmonary annulus growth after the modified Blalock-Taussig shunt in tetralogy of Fallot", Ann Thorac Surg. 98(3), pp 934-40.

15. Nguyễn Sinh Hiền, Nguyễn Văn Mão (2010), "Những thay đổi trong chiến lược điều trị tứ chứng Fallot tại Bệnh viện tim Hà nội”, Y học thực hành 2010, số 11, trang 57-60.

16. Phan Cao Minh, Huỳnh Thị Duy Hương, Vũ Minh Phúc (2011), Đ Đặc điểm trẻ tứ chứng Fallot được phẫu thuật sửa chữa hoàn toàn tại bệnh viện Nhi đồng 1 từ 11-2007 đến 52010",Y học Thành phố Hồ Chí Minh, tập 15, trang 240-246.

17. Nicholas Collins and Louise Harris (2009). "Late arrhythmia in tetralogy of Fallot: current approaches to risk stratification". Congenital diseases in the right heart. (7), pp 251-58.

18. P. Finnegan, R. Haider, R. G. Patel, L. D. Abrams, and S. P. Singh (1976), "Results of total correction of the tetralogy of Fallot: Long-term haemodynamic evaluation at rest and during exercise", British Heart Journal. (38), pp 934-42.

19. Reichart B, Nollert G, Fischlein T, Bouterwek S, Bohmer C, Klinner W (1997), "Long-term survival in patients with repair of tetralogy of Fallot: 36 years follow up of 490 survivors of the first year affter surgical repair", $J$ Am CollCardiol.(30), pp 1374-83. 